\title{
LUCHAS MIGRANTES EN CONTEXTOS DE TRÁNSITO MIGRATORIO, EL CASO DEL MOVIMIENTO MIGRANTE CENTROAMERICANO
}

\author{
Migrant struggles in transit: the case of the Central American \\ migrant movement
}

Amarela Varela Huerta

\begin{abstract}
Resumen. Este texto aborda un ejemplo concreto de organización de migrantes, el Movimiento Migrante Mesoamericano, que trabaja por los derechos de los migrantes en tránsito por México, de forma coordinada con organizaciones y familiares de migrantes víctimas de desaparición en su tránsito hacia Estados Unidos. Este estudio de caso es un ejemplo de luchas migrantes en contextos de tránsito, tipo específico de movimiento social que ha sido poco abordado en la literatura que piensa la acción colectiva de los migrantes. En el trabajo se analizan los actores, las prácticas, las alianzas y el contexto al que se enfrentan los activistas del movimiento en cuestión.
\end{abstract}

Palabras clave: luchas migrantes, transmigración, acción colectiva, movimientos sociales.

\begin{abstract}
This paper addresses a specific, little known example of grassroots migrant organization. The Mesoamerican Migrant Movement advocates for and advances the rights of migrants in transit through Mexico via collaboration with other migrant organizations and relatives of victims of disappearance while migrating to the United States. The case study is an example of migrant struggles in transit, which is a specific type of organizing that has received minimal attention in the literature about the collective action of migrants. The analysis touches upon the specific actors, practices, partnerships, and contexts that Mesoamerican Migrant Movement activists engage in their day to day efforts.
\end{abstract}

Keywords: migrant struggles, migration in transit, collective action, social movements.

\footnotetext{
1 Universidad Autónoma de la Ciudad de México. Ciudad de México, México.
} 
Cada año entre 200 y 400 mil personas $^{2}$, nadie sabe a ciencia cierta, atraviesan México por tierra desde Centroamérica para intentar establecerse en los Estados Unidos de Norteamérica. Los mexicanos los vemos en las calles, en las estaciones de autobuses, en los hospitales, en las vías de trenes, en nuestro quehacer cotidiano. También nos enteramos de su paso por México a través de los noticiarios de radio y televisión, de los diarios, del cine. Nos indigna la realidad a la que son sometidos: agredidos, violentados, extorsionados por los funcionarios que cobran del erario público o a manos de las redes criminales administradas desde el Estado. Las y los centroamericanos huyen de la violencia del mercado neoliberal que infringió todos los ámbitos de su vida cotidiana y generalizó el uso de la violencia, sobre todo contra las mujeres, ante gobiernos omisos y cómplices.

En el otoño de 2010, la masacre de 72 migrantes en tránsito hacia Estados Unidos ocurrida en el norteño estado de Tamaulipas visibilizó internacionalmente un fenómeno masivo, doloroso y producto de múltiples lógicas de impunidad en el corredor migratorio más nutrido del mundo. Desde entonces y hasta la fecha, las violaciones sistemáticas a los derechos humanos de las personas migrantes son noticia cotidiana en los diarios, su erradicación es objeto de diversos discursos de organismos internacionales e incluso gobiernos. No obstante, las políticas públicas, las leyes de extranjería y los acuerdos de gestión de las migraciones entre el gobierno norteamericano y sus vecinos del sur, siguen criminalizando la fuga de los migrantes que huyen de la violencia social, política y económica intentando llegar a Estados Unidos.

Según organizaciones de migrantes, quienes a su vez replican informes y estadísticas de organismos internacionales de todo tipo, en México los migrantes en tránsito son tratados como cuerpos desechables, con tal de frenar su paso se han puesto en marcha planes y programas de "gestión de la migración" como el Plan Frontera Sur de reciente implementación ${ }^{3}$, hasta convertir a México como el país más violento del mundo para los migrantes en tránsito por su territorio. Con más de 20.000 secuestros de migrantes por año, un aproximado de entre 72.000 a 120.000 inmigrantes desaparecidos y, desde el recrudecimiento de la

2 El tema de estadísticas concretas, correctas y verificables para aproximarnos a las migraciones centroamericanas representa un espejo perverso de las formas en que son gestionados los movimientos de personas. Según la fuente (organismos no gubernamentales, casas de refugio y apoyo a migrantes, organizaciones civiles y políticas, observatorios académicos, fuentes gubernamentales) desde 1995 y a la fecha el flujo promedio de "eventos" o intentos de cruce fronterizo (que no es lo mismo que personas migrantes) desde CA hacia EEUU oscila entre los 200 y los 430 mil. De tal suerte que, como en muchas otras dimensiones de las migraciones que nos ocupan, los estudiosos de este fenómeno caminamos a tientas. No podemos afirmar cuántos migrantes intentan el éxodo, cuántos lo logran, cuántos desaparecen en el intento.

3 Para una genealogía de la gestión securitaria externalizada de la transmigración por México, véase VARELA, Amarela. La securitización de la gubernamentalidad migratoria a través de externalización de fronteras estadounidenses en Mesoamérica. 
securitización/externalización de fronteras (2006-2015), el hallazgo de 24.000 cadáveres en tumbas anónimas en cementerios municipales, más 40.000 cuerpos no identificados en las morgues públicas ${ }^{4}$.

Este es pues el escenario sobre el que versa este artículo para pensar las formas de organización migrante. Un ejercicio reflexivo parte de la pregunta motor sobre qué tipo de organización es posible en estos escenarios de muerte y desapariciones masivas de migrantes. Qué luchas migrantes están tomando forma en México, un territorio convertido en un virtual tapón sangriento, mortal, para quienes intentan llegar a Estados Unidos.

Hablamos de luchas migrantes para referimos a nuevos tipos de identidades políticas colectivas que son nuevas porque involucran el agenciamiento político que se produce cuando los sujetos victimizados, los migrantes, se identifican entre sí por esa condición y se organizan para defenderse de las leyes que los extranjerizan permanente, a través de un repertorio de acciones que buscan contener $y$, eventualmente, erradicar los efectos que el racismo institucional y el racismo social tienen en las vidas cotidianas de estos migrantes. Como hemos dicho ya en otros trabajos, pues las luchas migrantes configuran además un nuevo campo de acción sociológica para los migrantólogos ${ }^{5}$, las luchas migrantes tienen como características principales el que son plurinacionales y pluriculturales, pues sus miembros suscriben tanto diferentes identidades culturales como culturas políticas; son transnacionales, pues generalmente actúan en diáspora de forma coordinada entre los lugares de origen y los de destino. Y, sobre todo, se caracterizan por ampliar la noción de ciudadanía, al ejercer intensamente derechos políticos que les están negados por la construcción legal de la ilegalidad por parte de los Estados involucrados.

Son luchas cuyo horizonte político es la desaparición de todas las leyes especiales para los extranjeros, luchas que proponen una resemantización de las nociones del derecho a permanecer y a pertenecer en condiciones de equidad a sociedades, de facto, pluriculturales. Luchas que engordan el dispositivo jurídico de "ciudadanía" hasta desbordarlo de su raíz nacionalestadocéntrica que emparenta la nacionalidad de un sujeto con el derecho al pleno ejercicio de su ciudadanía. Al demandar libertad de circulación y el derecho a permanecer en la sociedad elegida como de instalación, algunos migrantes se desmarcan de la noción de víctimas y reclaman ser considerados como interlocutores políticos, es decir, ejercen la ciudadanía que su condición de inexistentes les niega $^{6}$.

4 SÁNCHEZ, Martha. Recent issues on migration - US-Mexico-Central America.

5 VARELA, Amarela. Por el derecho a permanecer ya pertenecer: una sociología de la lucha de migrantes.

6 VARELA, Amarela. La ciudadanía instituida en la era de la resistencia: El movimiento migrante en Barcelona como agente de nuevos discursos sobre la ciudadanía. 
Este tipo de movimientos sociales ha sido pensado desde diferentes perspectivas por académicos y sus propios protagonistas y, afortunadamente, hoy podemos afirmar que abundan los textos en los que se les analizan ${ }^{7}$. No obstante, la literatura disponible para pensar luchas migrantes casi siempre se basa en ejercicios socioetnográficos de organizaciones de migrantes ya instalados en las metrópolis contemporáneas ${ }^{8}$. También hay una extensa literatura en la que se analizan casos de organizaciones de migrantes transnacionales, y se describen ejemplos de formas de organización en los territorios de origen de esos migrantes y allá donde consiguen afincarse, como el caso de las organizaciones de migrantes indígenas de Chiapas y Oaxaca ${ }^{9}$.

No obstante, en la sociología de las luchas migrantes nos hace falta robustecer la reflexión y las investigaciones de dos dimensiones de la migración: el tránsito y el retorno o deportación ${ }^{10}$. Nos hacen falta trabajos sobre formas de organización migrantes en territorios de tránsito de los mismos. De ahí que este trabajo se concentre en pensar un ejemplo concreto de organización de migrantes en México, frontera vertical para miles de personas que intentan llegar a Estados Unidos por tierra, mar y aire.

Dentro de la literatura disponible sobre las formas de organización de migrantes hay trabajos en los que se analizan las que llamamos las organizaciones que ejercen el "derecho a ser hospitalarias" con los transmigrantes. Estos trabajos detallan el movimiento de casas de refugio para migrantes ${ }^{11}$ su historia, sus desafíos, las labores que desarrollan y las formas en que los migrantes hacen uso de ellas. En México estas organizaciones de la hospitalidad son mayoritariamente de corte religioso, si bien existen ejemplos de organización ciudadana como el colectivo de mujeres "Las Patronas" que ofrecen comida en las vías del tren a los migrantes centroamericanos ${ }^{12}$. Las casas refugio y los colectivos antirracistas o que demandan el respeto a los derechos de los migrantes están diseminados por las rutas de los transmigrantes, y su labor consiste, principalmente en

\footnotetext{
Véase, apenas como ejemplo, el monográfico de la revista canadiense Refuge, v. 26, n. 2, en relación a las luchas contra las fronteras como prácticas políticas, donde se compilan experiencias de resistencias migrantes por todo el mundo, disponible en: < http://refuge.journals.yorku.ca/ index.php/refuge/issue/view/1828>.

8 NYERS, Peter, RYGIEL, Kim (eds.). Citizenship, migrant activism and the politics of movement.

9 PAZ, Miguel. Migración, Ciudadanía y Buen Vivir en comunidades Tsotsiles transnacionales; DOMÍNGUEZ SANTOS, Rufino. La experiencia del Frente Indígena Oaxaqueño Binacional: crisis interna y retos futuros.

${ }^{10}$ Para luchas sobre migrantes deportados véase el trabajo de ANDERSON, Jill, SOLIS, Nina. Los otros dreamers. México, 2014.

${ }^{11}$ CASILLAS, Rodolfo. La labor humanitaria y los organismos civiles: la experiencia de los albergues y casas de migrantes, realidades y desafíos; RUÍZ PARRA, Emiliano. Ovejas negras. Rebeldes de la iglesia mexicana del siglo XXI.

12 DI MATTEO, Angela. Las Patronas: ángeles al borde del infierno. Una conversación con Norma Romero Vásquez.
} 
ofrecer refugio y alimentación a, sobre todo, los centroamericanos que intentan Ilegar a Estados Unidos. Si bien desde la matanza de San Fernando en 2010, puede observarse la politización del discurso "humanitario" de estos actores, al fincarse en el Estado la responsabilidad de garantizar los derechos de los migrantes.

Además de estas luchas migrantes que ejercen el derecho a ser hospitalarios, existen organizaciones de migrantes (casi siempre deportados o varados en México) que consideramos incipientes formas de autoorganización de migrantes en territorios que son al mismo tiempo de expulsión, de tránsito, de instalación y de retorno forzado o voluntario, como lo es México. Y en este grupo de luchas es que cabe el ejemplo que desarrollamos en este texto es el caso del Movimiento Migrante Mesoamericano, al que hemos acompañado con diferentes estrategias de investigación acción participante a lo largo de 5 años, en coyunturas concretas de movilización.

\section{El Movimiento Migrante Mesoamericano, un caso de luchas de migrantes en territorios de tránsito}

El Movimiento Migrante Mesoamericano (MMM), más que colectivo, es red de activistas y esfuerzos por acompañar en su trayecto por México a los migrantes mexicanos y centroamericanos. El MMM surge en 2006 en el marco del retorno de un núcleo importante de activistas por los derechos de los migrantes en Estados Unidos. Algunos de estos activistas volvieron de manera voluntaria para ser parte de lo que se conoce como la primera “diputación migrante" (entre 2006 y 2009), encabezada por el antiguo activista del movimiento estudiantil del 68 exiliado por décadas en California, José Jaques Medina, que fue incluido como diputado plurinominal del partido de centro "izquierda" PRD ${ }^{13}$. Así, una parte fundamental del MMM la fundan estos migrantes retornados a México por su propia voluntad e inauguran una agenda binacional, es decir, apuestan por la incidencia política en las cámaras mexicanas para empujar reformas migratorias en Estados Unidos, al mismo tiempo que apuestan por transformar la realidad legal y cotidiana de los migrantes centroamericanos que atraviesan por México.

\footnotetext{
${ }^{13}$ La figura de diputado plurinominal está vigente en el sistema de partidos mexicano y se basa en el reconocimiento de "cuotas" de representación. Jacques Medina fue sumado a las listas de diputados por cuotas partidistas por el PRD. Este partido de centro izquierda enfrenta una grave crisis desde hace años por las disputas internas de corrientes pero, sobre todo, porque en septiembre de 2014, estando el estado de Guerrero gobernado por un miembro de ese partido fueron asesinados 6 jóvenes y otros 43 normalistas de Ayotzinapa desaparecieron sin que hasta el momento este instituto político haya aclarado los vínculos que sus afiliados que ocupaban los principales cargos de la administraron local responsable de esta masacre tienen con el crimen organizado.
} 
Otra parte fundamental de los activistas del MMM son los migrantes deportados de Estados Unidos, entre los que destacan la figura de Elvira Arellano ${ }^{14}$ y Rubén Figueroa, ambos activistas por los derechos de los migrantes que fueron deportados desde Estados Unidos y desde su aterrizaje forzado en México han mantenido una militancia activa denunciando las violaciones a los derechos humanos de los mexicanos en el exilio económico, pero de manera acentuada, han protagonizado acciones y ciclos de protesta por los derechos de los transmigrantes centroamericanos que transitan por México.

Finalmente un tercer perfil de activistas que forman parte del MMM son algunos sacerdotes que administran las casas de refugio para migrantes establecidas a lo largo de la ruta migratoria, concretamente, la que traza el llamado "Tren de la muerte", figuras como fray Tomás González del Albergue para migrantes La 72 ${ }^{15}$, en honor a los migrantes asesinados en Tamaulipas en 2010.

El MMM se define como mesoamericano porque esta categoría geográfica abarca desde Aztlán (hoy California) hasta los países del Ilamado Triángulo del norte o Centroamérica. Entrevistados sobre cuáles son las principales demandas de esta red de activistas y las estrategias para lograrlas, ellos plantean que la demanda es una, "todos los derechos para todos", pero en concreto en su ideal normativo figuran las apuestas de que la sociedad mexicana reconozca dos tipos de interlocutores entre los actores políticos contemporáneos centrales en México: los mexicanos en el extranjero (entre los que figuran los más de 12 millones de sin papeles en EEUU) y los transmigrantes centroamericanos.

Reconocer estas dos subjetividades políticas persigue que su voz, sus demandas y necesidades, sean consideradas como un tema en la agenda política nacional, lo que redundaría en el reconocimiento por parte de la sociedad mexicana y sus gobernantes del racismo social e institucional que estas dos diásporas padecen.

Para conseguir visibilizar lo que le pasa a los migrantes mexicanos, el MMM "utilizó" la deportación de Elvira Arellano para, a través de ponerla en contacto con organizaciones civiles, políticas y también con las cámaras legislativas explicar las consecuencias vitales de lo que se ha llamado la "deportabilidad"16.

${ }^{14}$ Elvira Arellano es un ícono en el movimiento contemporáneo por los derechos de los migrantes en EEUU. Durante la década del 2000 permaneció varias veces encerrada en iglesias de California, practicando lo que se conoce como el derecho al Santuario, que se asemeja bastante a la acción política de los migrantes en Francia y España cuando se encierran en iglesias para demandar, todos, los papeles o la regularización para poder permanecer en donde habitan. Para una lectura sobre la subjetividad política de Arellano y las prácticas que desarrolla véase DE GENOVA, Nicolás. Poder soberano y la "nuda vida" de Elvira Arellano. In AQUINO, Alejandra, DECOSSÉ Frédéric, VARELA, Amarela (coords.). Desafiando fronteras: control de la movilidad y experiencias migratorias en el contexto capitalista, p. 165-174.

${ }^{15}$ Cf. <https://www.La72.org>.

${ }^{16}$ Ver el texto de DE GENOVA, op. cit. 
Elvira Arellano es un ícono en el movimiento contemporáneo por los derechos de los migrantes en EEUU. Durante 2006 y 2007 protagonizó encierros en iglesias de Chicago, practicando lo que se conoce como el derecho al Santuario, una práctica con larga tradición de lucha en EEUU instaurada por los refugiados centroamericanos de las dictaduras y guerras en Centroamérica que usaban los recintos religiosos para manifestarse, pues "la migra" no podía intervenir dentro ${ }^{17}$. Elvira fue deportada cuando abandonó la iglesia en Chicago para participar en una movilización de migrantes en California, en donde fue arrestada y deportada a México. Hoy está de nuevo afincada en EEUU con un proceso de legalización de su estatus jurídico en marcha luego de que participara en acciones de desobediencia civil fronteriza en 2014, con otras mujeres mexicanas que demandaban al gobierno estadounidense que les dejara retornar con sus familias a ese país luego de haber sido deportadas a México $^{18}$.

Elvira forma parte actualmente de campañas concretas para demandar reformas migratorias que legalicen a los 12 millones de migrantes ilegalizados en EEUU, acompaña al movimiento de jóvenes Dreamers ${ }^{19}$ en acciones concretas y, sobre todo, impulsa y visibiliza las demandas de miles de familias de estatus legal mixto que se han visto separadas por la política de deportación masiva del actual gobierno (Comunicación personal con Elvira Arellano, 2016).

Con el objetivo de conseguir que los transmigrantes centroamericanos sean considerados un actor político, un hablante, en la agenda política y mediática mexicana el MMM se propuso analizar y acompañar la migración en ruta de centroamericanos por México, un trabajo que realizan sobre todo Rubén Figueroa y los religiosos de los albergues para migrantes bajo la premisa de que trabajar entre los protagonistas del fenómeno "...es donde está el trabajo, donde está la realidad y donde está la sabiduría y probablemente donde va a estar las respuestas" (Entrevista a Marta Sánchez, 2015).

Y ésta es la que se ha convertido en la tarea central del MMM, porque a través del trabajo de estudiar y acompañar a los transmigrantes descubrieron y

17 COUTIN, Susan. iSí, se puede! Los sin papeles en Estados Unidos y la lucha por la legalización en los primeros años del siglo XXI.

${ }^{18}$ Protestas en las zonas fronterizas en donde miembros de familias deportadas se "entregan" a la autoridad migratoria estadounidense, un trabajo complejo pero que apuesta por la reunificación de las familias. Y precisamente, producto de una de las movilizaciones más recientes en Tijuana, México, Elvira Arellano, deportada en 2008, ha vuelto a cruzar la frontera México-Estados Unidos, en 2014.

${ }^{19}$ El movimiento se refiere al conjunto de personas, colectivos y organizaciones de jóvenes en Estados Unidos que se autonombran como "Dreamers", por el DREAM Act, un proyecto de ley presentado al Congreso de los Estados Unidos en 2010 que buscaba regular la situación migratoria de quienes llegaron a Estados Unidos siendo menores de quince años y que han permanecido por más de cinco años ahí. 
tejieron complicidad política con la Caravana de Madres Centroamericanas ${ }^{20}$, mujeres centroamericanas que buscan a sus hijos desaparecidos en México, algunas desde hace más de 20 años, otras recientemente, pero que consiguieron reconocimiento mediático, público e interlocución con los gobernantes mexicanos solo después de la matanza de 72 migrantes en el rancho de San Fernando, en Tamaulipas en 2010. Con el reforzamiento de esta Caravana el MMM cubre varias líneas estratégicas de acción pues ésta sitúa el tema en la agenda nacional, otorga legitimidad al trabajo de los activistas de la organización, se consigue la solidaridad de la sociedad mexicana,

... es que después de hacer trabajo por ejemplo nos decían hace dos años, que antes pasaba el tren y les tiraban piedras [a los migrantes] y ahora pasa el tren y les tiran botellas de agua, entonces esos son los cambios que buscamos que no son generales ni son impactantes pero de uno por uno sumándolos si son importantes si son cambios reales, que nos los tumban a cada rato porque vuelve a aparecer el problema con toda la criminalización que hay y todos los desmadres que hacen las propias autoridades, pero vaya se va construyendo un poco de otra visión diferente de lo que es la migración (Entrevista Marta Sánchez, 2015).

Así pues, con la Caravana de Madres centroamericanas los activistas del MMM consiguen cambiar la percepción hacia la migración centroamericana que persiste en la racista sociedad mexicana, paradójicamente con millones de sus miembros en el exilio económico. Pero, de manera central, con la Caravana de Madres centroamericanas el MMM ha localizado a casi un centenar de migrantes desaparecidos por la frontera vertical que es México, es decir, ha construido estrategias de autodefensa y cuidado de los migrantes que el Estado mexicano, imbuido como está en una guerra de la que no quiere establecer un censo confiable sobre muertos y desaparecidos, los propios migrantes van encontrando estrategias de defensa del derecho a la vida en medio de esta política de muerte.

Con esta caravana y otras acciones el MMM aspira a modificar todo lo que tiene que ver con la responsabilidad del estado acerca de los desaparecidos, específicamente los migrantes en ruta hacia Estados Unidos. El MMM demanda que el estado detenga los crímenes en la ruta migratoria, que se persigan, enjuicien y sancionen las violaciones a los derechos fundamentales

\footnotetext{
${ }^{20}$ La caravana de Madres Centroamericanas es una iniciativa transnacional que desde hace más de una década se dedica a buscar a los hijos migrantes desaparecidos en su ruta por México hacia Estados Unidos. Esta hubiese representado otra postal para el artículo, pero por motivos de espacio no la he incluido. Un tipo de lucha migrante más compleja pues involucra estrategias de maternar la búsqueda, mecanismos feminizados de activismo. Para una descripción más amplia de esta lucha y sus implicaciones puede verse un texto que escribí en 2013: VARELA, Amarela. Del silencio salimos: la Caravana de madres hondureñas en México. Un ejemplo de resistencias en clave femenina al régimen global de fronteras. In AQUINO, DECOSSÉ, VARELA, op. cit.
} 
de los migrantes; lo que implicaría que el gobierno mexicano reconozca que los planes de contención de la migración, más que "ordenarla" o detenerla, aumentan la vulnerabilidad de los migrantes en tránsito porque estos planes de contención migratoria criminalizan el tránsito migratorio en los hechos y con ello provocan la diversificación de los caminos y las estrategias de quienes intentan Ilegar a Estados Unidos, caminos y estrategias que se entremezclan con las rutas más peligrosas en territorio mexicano, esas que usan los cárteles de la droga para operar.

Y en este tenor es que, como consecuencia de la complicidad política con las madres centroamericanas, desde 2012, miembros del MMM se desplazan anualmente por las regiones mayormente expulsoras de migrantes en América Central, en dichos desplazamientos, los activistas mexicanos construyen lo que llaman "puentes de esperanza", recontactando familias de migrantes concretos, pero sobre todo, construyendo un censo autogestionado de los migrantes desaparecidos. A través de sencillas fichas elaboradas a mano por los activistas migrantes o por los familiares de los migrantes, las familias de quienes se perdieron en el tránsito narran patrones de enganchamiento (sobre todo de mujeres) por parte de coyotes, patrones de zonas que en la jerga de los activistas se llaman "traga personas" como Tamaulipas o Coahuila, zonas controladas por los cárteles de la droga. A la ficha que se levanta en el quiosco itinerante del Censo Migrante por las zonas expulsoras, sencillo dispositivo móvil que consiste en una mesa y dos sillas, la papelería para las fichas y un megáfono para anunciar la llegada y el objetivo del censo cada vez que el quiosco se instala en las plazas centrales o avenidas principales de las ciudades y pueblos en los que se instala temporalmente ${ }^{21}$, los activistas del MMM suman fotocopias de papeles de identidad (credenciales, actas de nacimiento, pasaporte, lo que la familia tenga) y fotografías de los migrantes extraviados.

Esta labor subsana la carencia de mecanismos realmente efectivos de impartición de justicia transnacionales, como indica Rubén Figueroa, su principal promotor

la mayoría de los casos no están documentados, las familias nunca han denunciado la desaparición de sus familiares y los que lo hacen son rechazados por que las autoridades en Centroamérica les indican que no fue en sus países de origen donde se desaparecieron, en el caso de Honduras donde según los familiares algunos casos han sido denunciados ante cancillería, pero que solo les reciben la documentación y nunca más los vuelven a llamar para seguir las investigaciones y ante el Ministerio Publico no les reciben la denuncia, no existe ningún mecanismo regional

\footnotetext{
${ }^{21}$ Agradezco sinceramente el acceso que el MMM facilitó a esta investigación a dicho censo, en proceso de sistematización para la denuncia pública de dichos patrones en el enganchamiento y desaparición de miles de personas.
} 
entre los países de origen, tránsito y destino para denunciar la desaparición de los migrantes a pesar que el número de víctimas son miles²2.

En este como en otros frentes, esta y otras organizaciones de migrantes están realizando labores que corresponden a las instituciones encargadas de la procuración de justicia. Incluso hay un grupo de organizaciones que desde 2015 impulsan instrumentos transnacionales de búsqueda y acceso a la justicia para personas migrantes, que pondría en coordinación a las agencias nacionales de los países centroamericanos con el mexicano ${ }^{23}$, sin que se concreten acciones o mecanismos reales y efectivos hasta ahora ${ }^{24}$.

Además de este ejercicio de autoprocuración de justicia, el MMM realiza otras estrategias concreta para visibilizar la crisis humanitaria que padecen los centroamericanos, como el llamado "Viacrucis migrante", una manifestación que se ampara bajo el esquema religioso de la semana santa pero que es una denuncia social fuerte contra lo que está sucediendo. Implica marchar sobre las vías, sobre el tren, todo lo que se puede, porque varios viacrucis fueron en el tren, una estrategia que el año pasado ya consiguió una visibilidad mediática considerable que redundo por cierto en acciones de la policía migratoria inéditas e interesantes ${ }^{25}$.

Finalmente, para conseguir los derechos para todos, el MMM prioriza el trabajo de cabildeo legislativo para incidir en la creación de un marco normativo de extranjería en México. En concreto apuestan por adecuar las leyes de extranjería que la política de externalización de fronteras dictó para México desde la década pasada, para que los derechos de los migrantes no se supediten a los criterios de seguridad nacional. Y para eso toman parte de espacios institucionales a la vez que performan acciones directas para presionar a senadores y diputados.

Cuestionada sobre esta última línea de trabajo, sobre todo partiendo de que otras luchas en el mundo plantean como demanda la derogación de leyes que les extranjerizan. Una de las voceras del MMM reflexionó:

... Nosotros nos basamos mucho en lo que paso en Estados Unidos con la ley de migración, cuando había propuestas más o menos decentes que no estaban completas y que les faltaba mucho, pero estaban, y estaban los diputados a punto de aprobarla, todo el mundo se puso en contra porque

${ }^{22}$ FIGUEROA, Rubén. México, el triángulo de las bermudas para los migrantes.

${ }^{23}$ RED REGIONAL VERDAD Y JUSTICIA PARA PERSONAS MIGRANTES. Informe alternativo presentado al Comité contra la Desaparición Forzada en vista del examen del informe de México durante la $8^{a}$ sesión del Comité, de 2 a 13 de febrero de 2015.

${ }^{24}$ Si bien es importante anotar que en diciembre de 2015, el gobierno mexicano avanzó en la creación unilateral de las instancias que permitirían el instrumento transnacional. Véase: $<$ http:// fundacionjusticia.org/acuerdo-de-crentes-de-la-pgr/>. Consultado en: 10.2016.

${ }^{25}$ VACA GARCÍA, María. De la clandestinidad a la libertad de tránsito. Migrantes centroamericanos exigiendo sus derechos. 
no era todo. Resultado: no hubo nada. Y no ha podido haber nada. Todavía estamos en que no hay nada y mientras siguieron deportando, separando familias, siguió la criminalización y siguió el sufrimiento de la gente. Por ejemplo decíamos, si se hubiera aprobado aquella ley de migración cuando menos la mitad de los indocumentados hubieran pasado, son 4 o 5 millones de gentes, "ah no pero es que no era todo", ah era todo o nada (Entrevista Marta Sánchez, 2015).

De esta reflexión es que se sostiene el actuar político del MMM que combina la incidencia política, el cabildeo y la acción directa para detener el horror que padecen los migrantes centroamericanos que se ven obligados a migrar y transitar por México.

\section{A modo de conclusión... Luchas migrantes en países tapón}

En este trabajo reflexionamos sobre las formas de acción colectiva, los protagonismos, las alianzas, las estrategias para construir un movimiento social en defensa de los derechos de los migrantes en contexto de tránsito migratorio. Poniendo especial énfasis en el interés que tenemos de comenzar a documentar luchas migrantes en territorios de tránsito pues este fenómeno ha sido poco analizado en la literatura especializada sobre migraciones y movimientos sociales. Nos interesa concluir el texto haciendo énfasis en el escenario donde esta lucha migrante toma forma. Un país de tránsito migratorio.

México es conocido en la literatura especializada en migraciones globales como el segundo de los territorios expulsores de mano de obra; la nación con una de las diásporas más importantes viviendo en el "exilio económico" en Estados Unidos y, de un tiempo a la fecha, como uno de los ejemplos más siniestros en materia de violaciones sistemáticas de derechos humanos de transmigrantes. Hoy por hoy, México sólo es comparable con países como Marruecos o Turquía, en términos de sus modelos de extranjería y las labores por fuera del estado de derecho que los gobiernos implementan, de ahí que se haya generalizado la idea entre migrantes de que México es un país "tapón".

Un país tapón es un territorio donde la frontera se verticaliza en toda su geografía, son países circunvecinos a regiones metropolitanas, como la Unión Europea o Estados Unidos. Como se dijo ya, Marruecos, Turquía y México son tres ejemplos concretos de país "tapón", naciones que paradójicamente tienen largas tradiciones migratorias, pero que se les han impuesto el papel de "puerta trasera" para frenar a los millones de migrantes forzados, asilados políticos o migrantes económicos, deportándoles masivamente antes de que consigan llegar a los países del norte a los que se dirigían. 
Desde la perspectiva de diversos investigadores, a este fenómeno se le conoce como "externalización de fronteras"26, suma de dispositivos policíacos y militares en zonas fronterizas que trasladan las formas de gestionar los movimientos de personas en países de tránsito de migrantes a través de tratados y acuerdos lo mismo de cooperación al desarrollo, de libre mercado, pero sobre todo, relativos a seguridad nacional. Dispositivos discursivo/legales que se traducen en cooperación policial y militar para la lucha contra el terrorismo y de combate a la "inmigración irregular", firma de acuerdos de readmisión o deportación masiva de migrantes, la "gestión ordenada" de las "cuotas de migración legal" de los países involucrados en los tratados.

Este modelo de gubernamentalidad migratoria, intenta desalentar el éxodo de los migrantes, o si éste ya se produjo, se encarga de la intercepción, detención y deportación de los migrantes a través de una compleja red de terciarización política y económica de dispositivos que involucran lo mismo centros de detención para solicitantes de asilo y migrantes "económicos" que la construcción de infraestructura militar para la "contención" de los movimientos humanos. Todo ello en territorios donde existen evidencias y bien documentadas de alarmantes niveles de impunidad y violación a los derechos fundamentales ${ }^{27}$.

Esta suma de medidas ha provocado que los tránsitos de los migrantes se produzcan por territorios más alejados, amplificándose con ello las vulneraciones a sus derechos humanos. Lo cual resulta obvio pues, cuando los migrantes se percatan de que las rutas migratorias tradicionales están repletas de retenes de diferentes cuerpos policiales con la reputación de extorsionar, torturar y hasta desaparecer a los transmigrantes, estos últimos optan por internarse aún más alejados, territorios que están bajo el control del llamado "crimen organizado". Así, la espiral de violencia de la que huyen se amplifica, hasta convertirse en casi inenarrable por la crueldad de las situaciones que se reportan.

Es en este escenario y contexto que se explica la urgencia de acompañar desde la academia la construcción de organizaciones de migrantes en territorios de tránsito migratorio que desde la más extrema precariedad jurídica defienden a sus iguales de la violencia de Estado y de los grupos del crimen organizado. Acompañar, describir, pensar sus acciones y demandas, explicarlas en términos académicos y producir conocimiento con base en los saberes que los migrantes organizados generan en su quehacer cotidiano no solo es urgente, sino que es imprescindible para desmontar con argumentos de las propias víctimas del llamado régimen global de fronteras, el modelo de racismo social e institucional que hoy tiene sumida a toda la humanidad en una de sus crisis de derechos fundamentales más agudas en su historia contemporánea.

${ }^{26}$ FERNÁNDEZ BESSA, Cristina. Introducción: los límites del control.

27 VARELA, Amarela. La securitización de la gubernamentalidad migratoria a través de externalización de fronteras estadounidenses en Mesoamérica. 


\section{Bibliografía}

AQUINO, Alejandra; DECOSSÉ, Frédéric; VARELA, Amarela (coords.). Desafiando fronteras: control de la movilidad y experiencias migratorias en el contexto capitalista. [Sur+ Ediciones], Oaxaca: Frontera Press, 2013.

CASILLAS, Rodolfo. La labor humanitaria y los organismos civiles: la experiencia de los albergues y casas de migrantes, realidades y desafíos. In CHIARELLO, Leonir M. (coord.). Las políticas públicas sobre migraciones y la sociedad civil en América Latina. Los casos de Argentina, Brasil, Colombia y México. NY: Scalabrini International Migration Network, 2011.

COUTIN, Susan. iSí, se puede! Los sin papeles en Estados Unidos y la lucha por la legalización en los primeros años del siglo XXI. In SUÁREZ-NAVAZ, Liliana; MACIÁ, Raquel; MORENO, Angela. Las luchas de los sin papeles y la extensión de la ciudadanía. Perspectivas críticas desde Europa y Estados Unidos. Madrid: Traficantes de Sueños, 2007, p. 155-183.

DE GENOVA, Nicolás. Poder soberano y la "nuda vida" de Elvira Arellano. In AQUINO, Alejandra; DECOSSÉ, Frédéric; VARELA, Amarela (coords.). Desafiando fronteras: control de la movilidad y experiencias migratorias en el contexto capitalista. [Sur+ Ediciones], Oaxaca: Frontera Press, 2013, p. 165-174.

DI MATTEO, Angela. Las Patronas: ángeles al borde del infierno. Una conversación con Norma Romero Vásquez. Altre Modernità, n. 13, 2015, p. 180-185.

DOMÍNGUEZ SANTOS, Rufino. La experiencia del Frente Indígena Oaxaqueño Binacional: crisis interna y retos futuros. In FOX, Jonathan; RIVERA-SALGADO, Gaspar (coords.). Indígenas mexicanos migrantes en los Estados Unidos. México: Universidad Autónoma de Zacatecas-Porrúa, 2004.

FERNÁNDEZ BESSA, Cristina. Introducción: los límites del control. In Frontera Sur. Nuevas políticas de gestión y externalización del control de la inmigración en Europa. Barcelona: Virus Editorial, 2008, p. 7-12.

FIGUEROA, Rubén. México, el triángulo de las bermudas para los migrantes. 2015. Disponible en: <https://movimientomigrantemesoamericano.org/2015/01/31/ mexico-el-triangulo-de-las-bermudas-para-los-migrantes/>. Consultado en: 10.2016.

GABRIELLI, Lorenzo. La inmigración "informal" en la relaciones entre Europa y África Subsahariana. In CHUECA, Ángel (coord.). Derechos Humanos, inmigrantes en situación irregular y Unión Europea. Valladolid: Lex Nova, 2010, p. 25-38.

NYERS, Peter; RYGIEL, Kim (eds.). Citizenship, migrant activism and the politics of movement. Routledge, 2012.

RED REGIONAL VERDAD Y JUSTICIA PARA PERSONAS MIGRANTES. Informe alternativo presentado al Comité contra la Desaparición Forzada en vista del examen del informe de México durante la $8^{a}$ sesión del Comité, de 2 a 13 de febrero de 2015. 2015. Disponible en: <http://fundacionjusticia.org/cms/ wp-content/uploads/2015/02/Informe-Adicional-a-CED-Dic-2014.pdf>. Consultado en: 10.2016 . 
RUÍZ PARRA, Emiliano. Ovejas negras. Rebeldes de la iglesia mexicana del siglo XXI. México: Océano, 2012.

SÁNCHEZ, Martha. Recent issues on migration - US-Mexico-Central America. 2015. Disponible en: <https://www.academia.edu/14135885/Recent_issues on_migration_US-Mexico-Central_America >. Consultado en: 03/2016.

PAZ, Miguel. Migración, Ciudadanía y Buen Vivir en comunidades Tsotsiles transnacionales. Tesis doctoral. México: UAM-Xochimilco, 2016.

VACA GARCÍA, María. De la clandestinidad a la libertad de tránsito. Migrantes centroamericanos exigiendo sus derechos. Ponencia en el I Congreso de Movimientos Sociales. Octubre de 2016.

VARELA, Amarela. La securitización de la gubernamentalidad migratoria a través de externalización de fronteras estadounidenses en Mesoamérica. Contemporánea, n. 4, julio-diciembre, 2015.

VARELA, Amarela. La ciudadanía instituida en la era de la resistencia: El movimiento migrante en Barcelona como agente de nuevos discursos sobre la ciudadanía. In BOLAÑOS, Bernardo (coord.). Biopolítica y migración el eslabón perdido de la globalización. México: UAM Cuajimalpa, 2015.

VARELA, Amarela. "Luchas migrantes": un nuevo campo de estudio para la sociología de los disensos. Andamios. Revista de Investigación Social, v. 12, n. 28, Mayo-Agosto 2015, p. 145-170.

VARELA, Amarela. Por el derecho a permanecer ya pertenecer: una sociología de la lucha de migrantes. Madrid: Traficantes de Sueños, 2013.

Recibido para publicación en 15.10.2016

Aceptado para publicación en 04.11.2016

Received for publication in October 15

Accepted for publication in November 04 ${ }^{\text {th }}, 2016$

ISSN impresso 1980-8585

ISSN eletrônico 2237-9843

http://dx.doi.org/10.1590/1980-85852503880004803 